\title{
Qualidade na prestação de serviços fisioterápicos - estudo de caso sobre expectativas e percepções de clientes
}

\author{
Adriano Mendonça Souza \\ Deizi Griebeler \\ Leoni Pentiado Godoy
}

UFSM

\begin{abstract}
Resumo
O presente artigo aborda a qualidade na prestação de serviços fisioterápicos, através da comparação entre expectativas e percepções de clientes de uma clínica de Fisioterapia da cidade de Santa Maria, RS. Para avaliação da qualidade, utilizou-se a Escala SERVQUAL, composta por vinte e duas questões, sendo que, em doze delas, a percepção de qualidade foi superior às expectativas. Três questões apresentaram médias semelhantes entre expectativas e percepções e, em sete questões, as expectativas foram superiores às percepções. Os dados também foram submetidos à Análise Estatística Multivariada, a fim de verificar a presença ou não de questões redundantes na Escala SERVQUAL adaptada à Fisioterapia. Mediante critérios de exclusão, nove questões foram eliminadas do questionário sem perda significativa em sua abrangência e confiabilidade. Este estudo possibilitou detectar pontos de melhoria nos serviços prestados pela clínica constituinte do caso, além de sugerir uma versão mais enxuta para a Escala SERVQUAL.
\end{abstract}

Palavras-chave

Qualidade, Escala SERVQUAL, Fisioterapia, Análise Multivariada e Análise de Conglomerados.

\section{Rendered fisioterapy quality services - expectations and perceptions of customers}

\begin{abstract}
The present study approaches quality in the physiotherapy services rendered through the comparison between expectations and customers' perceptions. The study was developed in a Physiotherapy clinic from Santa Maria's city - RS. SERVQUAL scale composed by twenty two questions was used to evaluate the quality services. Quality perception was higher than expectations in twelve questions. Three questions presented have a similar average behavior between the expectations and perceptions and in seven the expectations were higher than perceptions. Data were also submitted to Multivariate Exploratory Techniques, with the purpose to verify the presence or not of redundant subjects in the SERVQUAL scale adapted to Physiotherapy. Multivariate Exploratory Techniques allowed retreat redundant questions through exclusion criteria. Nine questions were eliminated to the questionnaire without confiability and abrangence loss. This study made possible to detect improvement points in the services rendered by the clinic, furthermore it proposed a SERVQUAL scale with smaller number of questions without significant loss in its representation.
\end{abstract}

Key words

Quality, SERVQUAL scale, Physiotherapy, Multivariate analysis and Conglomerate analysis. 


\section{INTRODUC̣̃̃O}

A qualidade é, freqüentemente, considerada como um dos pontos determinantes do sucesso de empresas e prestadores de serviço. Oferecer produtos e serviços com qualidade passou a ser condição de preexistência no mercado, não mais se configurando como estratégia de diferenciação. Organizações pouco atentas à qualidade de seus serviços correm o risco de perder competitividade e, em conseqüência, a sua fatia de mercado.

Além disso, programas de qualidade que não levem em conta o significado de qualidade para os clientes não terão resultados satisfatórios. Para se conseguir uma contínua melhora na prestação dos serviços, o prestador deve compreender como os serviços são avaliados na ótica do consumidor e mensurá-los periodicamente.

Para Grönroos (2003), a qualidade apresenta duas dimensões distintas: a qualidade técnica diz respeito ao que é oferecido ao cliente a fim de satisfazê-lo, e a qualidade funcional refere-se a como o serviço é prestado. $\mathrm{Na}$ área da saúde, percebe-se um grande avanço na qualidade técnica, sendo considerável a produção científica destinada ao conhecimento da etiologia e tratamento das doenças. No entanto, o número de estudos que abordam a qualidade funcional da prestação de serviços de saúde é relativamente pequeno, o que evidencia a carência de conhecimentos nessa área.

O setor da saúde, apesar de inserido no setor de serviços, possui características específicas e completamente diferenciadas dos outros serviços, devido à natureza de sua atividade intrinsecamente ligada à vida humana. Garvin (1990) destacou três singularidades que marcam as organizações de saúde: a) falta de clareza na conexão entre entradas e saídas, muito em função do tempo necessário para os resultados manifestarem-se; b) os pacientes podem ter dificuldades em avaliar aspectos técnicos; c) os grandes hospitais operam com duas linhas de autoridades distintas, o pessoal administrativo e os médicos, em vez da pirâmide de autoridade única predominante nas demais organizações.

Segundo Santos (2004), ao fazer um julgamento sobre a qualidade na prestação de serviços de saúde, os pacientes baseiam suas percepções nos pontos em que se sentem mais qualificados para julgar. Quando o consumidor se encontra em posição inferior para avaliar produtos ou serviços que sejam tecnicamente complexos, opta por utilizar outras dimensões que não as técnicas para efetuar sua avaliação.

Por isso, perceber a visão dos clientes em relação à qualidade funcional dos serviços de saúde pode constituir-se num diferencial importante para a satisfação e fidelização dos mesmos, pois, segundo Deming (1990) e Paladini (1995), "conhecer as expectativas da clientela" constitui-se no princípio fundamental da qualidade. Dentro dessa perspectiva, a presente pesquisa objetivou mensurar a qualidade na prestação de serviços fisioterápicos de Pilates, através da comparação entre expectativas e percepções dos clientes de uma clínica de Santa Maria - RS. Além disso, verificou, com base na Estatística Multivariada, a existência ou não de questões redundantes na Escala SERVQUAL adaptada à Fisioterapia e sugeriu uma versão mais enxuta para a Escala SERVQUAL, uma vez que foram detectadas questões redundantes.

A presente pesquisa é relevante, pois abordou a qualidade funcional da prestação de um serviço de Fisioterapia e não a sua qualidade técnica, a qual se constitui no foco da maioria das pesquisas na área da saúde. Como a Escala SERVQUAL é genérica e permite adaptações, diferentes segmentos do setor de saúde poderão beneficiar-se desta pesquisa para avaliar a qualidade na prestação de seus serviços, com vistas à fidelização de seus clientes. Além disso, o emprego da Estatística Multivariada nos dados provenientes da Escala SERVQUAL possibilitou um entendimento global dos resultados e uma correlação entre as variáveis, o que também se configura num diferencial.

\section{QUALIDADE EM SAÚDE}

Urdan (2001) chamou a atenção sobre as particularidades da qualidade de serviços de cuidado à saúde e se os princípios e técnicas genéricos de qualidade de serviços poderiam ser transferidos aos cuidados à saúde. France e Grover (1992) argumentaram que o produto do serviço de saúde é mais complexo do que outros serviços ao consumidor, por cinco razões:

1) Serviços de saúde são, provavelmente, os mais intangíveis de todos os serviços, pois, além de não poder experimentar o serviço previamente à compra, o consumidor, freqüentemente, não pode avaliá-lo, mesmo após o consumo. Alguns serviços médicos (como uma intervenção cirúrgica) podem constituir-se em uma experiência única ao longo da vida de um indivíduo, ao passo que outros serviços são experimentados várias vezes durante a vida. Gemmel et al. (2002) acrescentaram que a avaliação da qualidade em saúde é mais subjetiva que objetiva, porque os serviços são complexos, heterogêneos e o seu consumo e produção ocorrem simultaneamente.

2) Descasamento entre as expectativas do cliente e a entrega efetiva pode ser maior para os serviços de saúde. A individualidade de cada paciente, quanto aos seus aspectos psicológicos e condições de saúde, interfere no resultado da prestação de serviço de saúde.

3) A demanda por serviços de saúde é menos previsível, podendo ser afetada pelo surgimento repentino de um vírus, uma calamidade da natureza ou um acidente. Essa imprevisibilidade dos serviços de saúde exacerba a perecibilidade dos mesmos. 
4) A distinção entre o tomador de decisão e o cliente é mais confusa nos serviços de saúde. Após a decisão inicial de procurar um fornecedor tomada por um paciente ou sua família, a maioria das outras decisões específicas de compra de serviços de saúde é tomada (ou fortemente influenciada) por um fornecedor (profissional da saúde ou hospital).

5) Quando uma terceira parte (fonte pagadora) cobre os custos dos serviços de saúde, os clientes tendem a não ter elasticidade em relação a preço, ou seja, usar bem o dinheiro gasto com contas hospitalares não é uma preocupação na hora da compra.

Mirshawka (1994) definiu os três tipos de qualidade no serviço de saúde, os quais se encontram intimamente entrelaçados, embora dirigidos a segmentos distintos: a qualidade clínica referese à equipe de saúde, sendo determinada pelos médicos, enfermeiras e outros provedores do serviço de saúde. Engloba conceitos de saúde pública como morbidade (índice de doentes em uma comunidade), mortalidade e taxas de infecção hospitalar. Em contrapartida, pesquisas com pacientes e outros clientes indicam que, para eles, a qualidade deve ser totalmente voltada para a satisfação das expectativas do paciente. Ao descrever qualidade voltada para o cliente, termos como atenção, cuidado, comunicação, preocupação, empatia, etc., ganham destaque, em detrimento de aspectos técnicos da prestação do serviço. Grönsroos (2003) chamou essa dimensão de qualidade funcional. O terceiro tipo de qualidade é a qualidade econômica ou orientada para as finanças. Esse é um componente relativamente novo da qualidade nos serviços de saúde, pois leva em conta, também, os aspectos financeiros da qualidade. Para Mirshawka (1994, p. 39), "quando a atenção é excessiva, ela não resulta em melhor qualidade, mas apenas em custos maiores; portanto, o excesso de atenção só é mais caro, não correspondendo a aumento de qualidade, constituindo-se em um desperdício”.

A qualidade do pacote de serviços oferecido é, em grande parte, intangível e, portanto, difícil de medir e controlar. Para Zeithaml e Bitner (2003) e Choi et al. (2004), serviços médicos, entre outros, são altamente complexos, e geralmente não fica claro qual é o resultado técnico. Segundo esses autores, a maioria dos pacientes não possui conhecimento suficiente na área da saúde para avaliar se o serviço prestado foi realizado adequadamente ou, até, se o mesmo era realmente necessário. Assim, para avaliá-lo, o paciente busca subsídios nas evidências de interesse e preocupação dos profissionais com sua saúde e bem-estar (DONABEDIAN, 1990; GEMMEL et al., 2002).

Desse modo, para que a gestão da qualidade em saúde obtenha sucesso, deve-se ter como foco o paciente e a me- lhoria dos processos envolvidos. Quanto mais difundidos os princípios de qualidade dentro de organizações de saúde, maiores as chances de sua importância ser reconhecida e maiores os esforços coletivos para a sua obtenção.

\section{MENSURAC̣ÃO DA QUALIDADE EM SERVIC̣OS}

A importância dos serviços demanda a necessidade de se empreender esforços em relação à mensuração da qualidade nos serviços prestados. Nesse sentido, ao longo do tempo, diversos pesquisadores têm dedicado esforços nesta área, buscando aprimorar sua conceituação e desenvolver técnicas de medição.

\section{ferecer produtos e serviços com qualidade é condição de preexistência mercado, não mais se configurando estratégia de diferenciação.}

Parasuraman, Zeithmal e Berry (1985) desenvolveram um modelo para avaliação da qualidade em serviços, denominado SERVQUAL, com base nas dimensões de qualidade para serviços. Segundo Miguel e Salomi (2004), o instrumento SERVQUAL é muito difundido e referenciado em publicações. Esses mesmos autores afirmam que não existe ainda um consenso na literatura sobre qual modelo é mais apropriado. "Alguns trabalhos empíricos, como o de Lee et al. (2000), apontam que o modelo SERVPERF retrata melhor a qualidade de serviços que o modelo SERVQUAL" (MIGUEL; SALOMI, 2004, p. 29). No entanto, no entender desses autores, ainda não é possível ser conclusivo sob esse aspecto. Johnston e Clark (2002) e Fitzsimmons e Fitzsimmons (2005) afirmaram que o SERVQUAL é um dos instrumentos mais conhecidos para avaliar a qualidade do serviço.

Parasuraman, Zeithaml e Berry (1991) chamaram a atenção sobre a periodicidade de pesquisas sobre qualidade de serviços: o SERVQUAL deve ser usado periodicamente e em conjunto com outras formas quantitativas e qualitativas de medição da qualidade de serviços. Quanto à sua aplicabilidade, a escala SERVQUAL é utilizada para medir a qualidade de serviço em vários setores, assim como serve de base em estudos publicados sobre esse tema. Karatepe, Yava e Babakus (2005) sugeriram a existência de alguns aspectos, potencialmente universais, na prestação de serviço. Em vista disso, tais autores afirmaram que não há a necessidade de se desenvolver metodologias específicas para avaliação da qualidade em diferentes setores de serviço, uma vez que a 
Escala SERVQUAL pode ser adaptada a diferentes contextos. O que se deve utilizar são diferentes ferramentas para a análise da Escala SERVQUAL. Por exemplo, a maioria dos trabalhos utiliza apenas estatística descritiva para analisar os dados provenientes da Escala, a qual não reflete o interrelacionamento das variáveis. Nesta pesquisa, empregaramse métodos multivariados que possibilitaram uma visão global dos entrevistados nos diversos quesitos, levando em consideração a correlação entre as variáveis, o que também é um diferencial apresentado. As técnicas multivariadas estão amplamente discutidas em Mingoti (2005), Hair et al. (2005), Souza e Vicini (2005), Malhotra (2001), Pereira (2001), Khattree e Naik (2000).

Quanto à entrega do questionário aos clientes, tal tarefa foi executada sempre pela mesma pessoa, a qual repassava informações sobre objetivos da pesquisa e preenchimento dos questionários. A pesquisa foi entregue dentro de um envelope e solicitou-se aos participantes que a devolvessem com o envelope colado para que somente o pesquisador tivesse acesso às respostas.

Após a coleta de dados, a fase seguinte da pesquisa foi análise e interpretação dos resultados. Primeiramente, foram tabulados os dados provenientes da Escala SERVQUAL adaptada para a presente pesquisa, com um total de 44 questões envolvendo a qualidade percebida e a expectativa sobre a prestação do serviço. Em cada questão, o participante da pesquisa foi instruído a assinalar a nota correspondente à sua avaliação, variando de $1 \mathrm{a}$ 7. As menores notas correspondiam à baixa qualidade e as maiores, à alta qualidade dos serviços prestados. As questões foram agrupadas nas cinco dimensões da qualidade: confiabilidade, empatia, sensibilidade, segurança e tangíveis e submetidas à Estatística Descritiva para obtenção de suas

Diante dos pontos levantados anteriormente, destacase, novamente, a importância de avaliações periódicas sobre a qualidade dos serviços prestados. Avaliações isoladas podem produzir resultados não condizentes com a realidade do serviço oferecido, em função das muitas limitações e variáveis inerentes à mensuração da qualidade em saúde.

\section{METODOLOGIA DA PESQUISA}

A presente pesquisa classifica-se como pesquisa qualitativa e quantitativa que utiliza métodos descritivos uni e multivariados. O estudo de caso foi a técnica de pesquisa adotada para avaliar a qualidade na prestação de serviços fisioterápicos, sob o julgamento de praticantes do Método Pilates de uma clínica de Fisioterapia da cidade de Santa Maria, RS, durante o primeiro semestre de 2006.

Quanto à coleta de dados, esta ocorreu de duas formas: a pesquisa teve início com a busca de dados secundários disponíveis em revistas especializadas, periódicos, dissertações, teses e publicações legais - que forneceram subsídios para a fundamentação teórica do presente trabalho e seguiu com a coleta de dados primários, utilizandose a Escala SERVQUAL ilustrada em Fitzsimmons e Fitzsimmons (2005).

Anteriormente à coleta de dados, o questionário foi entregue a cinco clientes de Pilates, com diferentes graus de escolaridade, para verificar sua clareza e o entendimento das questões. As respostas obtidas não demonstraram dificuldades de compreensão, não denotando necessidade de alterar termos ou frases. médias aritméticas, referentes à qualidade percebida e à expectativa.

Posteriormente, os dados foram submetidos à Análise Estatística Multivariada, através do software Statistica, versão 7.0. A primeira técnica aplicada, referente à Análise Multivariada, foi a Análise de Agrupamentos. Através dela foi possível identificar quais variáveis pertenciam a um mesmo grupo, ou seja, quais questões apresentavam as mesmas características sob a ótica do cliente. O objetivo de aplicar Análise de Agrupamentos foi retirar do questionário as variáveis que possuíssem significados muito semelhantes para os clientes e, assim, eliminar questões redundantes. Para tanto, somente os dados coletados na primeira parte do questionário, referentes às EXPECTATIVAS do cliente, foram utilizados, pois o objetivo era propor um questionário mais enxuto. Se, por outro lado, as PERCEPÇÕES dos clientes fossem tomadas como base para a realização da Análise de Agrupamentos, o questionário proposto ficaria vinculado à realidade da clínica participante do estudo de caso.

Quanto ao coeficiente de parecença, adotou-se a distância euclidiana como critério de parecença e, quanto ao método de agrupamento, optou-se pela ligação simples. A forma gráfica escolhida para apresentar os dados submetidos à Análise de Agrupamentos foi o dendograma. As variáveis com o mesmo grau de informação, isto é, aquelas com a mesma altura no dendograma foram, paulatinamente, retiradas e a Análise de Agrupamentos foi realizada novamente. Dessa forma, verificou-se a formação de novos grupos e pôde-se, assim, observar que a variável carregava o mesmo nível de informação. Destaca-se que a retirada das variáveis 
não ocorreu de forma aleatória, mas de acordo com critérios estabelecidos pelo pesquisador, sendo eles:

1o critério: identificar as questões pertencentes a uma mesma dimensão da Escala SERVQUAL dentro do mesmo cluster;

2o critério: analisar quais questões de uma mesma dimensão, pertencentes ao mesmo cluster, convergiam para uma idéia única;

3o critério: após as etapas 1 e 2 , manter as questões mais abrangentes e/ou mais adequadas dentre as analisadas e excluir as demais.

A segunda técnica Multivariada aplicada no estudo foi a Análise Fatorial. Aplicou-se a Análise Fatorial a duas situações: no questionário completo, com as 22 questões, e no questionário com número reduzido de questões pela Análise de Agrupamentos, de forma a verificar se os fatores gerados englobavam as mesmas questões em ambas as situações. A Análise Fatorial também foi aplicada, com o objetivo de verificar se houve perda de representatividade da Escala SERVQUAL reduzida (após a retirada de nove questões), quando comparada com a representatividade da Escala adotada neste estudo de caso (com 22 questões).

Para realizar a Análise Fatorial, teve-se que observar:

- a matriz de correlação para verificar a estrutura de relacionamento das variáveis e a estimação dos autovalores e autovetores;

- seleção dos autovalores;

- seleção das variáveis de maior representatividade dentro de cada fator, pela correlação dos fatores com as variáveis originais e/ou pela inspeção das cargas fatoriais com valor significativo acima de 0,7 ;
- interpretação dos fatores gerados com o questionário completo, em relação às variáveis de maior importância.

\section{ANÁLISE E DISCUSSÃO DOS RESULTADOS}

Estavam aptos a participar do estudo todos os clientes da clínica de Fisioterapia que tivessem praticado ao menos cinco sessões de Pilates no período de março a junho de 2006, o que possibilitou constituir uma população de 98 clientes. Utilizou-se um erro amostral de 5\%, dimensionando-se uma amostra representativa composta de pelo menos 78 respondentes. Como 86 questionários respondidos retornaram ao pesquisador, obteve-se uma margem de segurança com os questionários extras respondidos. Vale lembrar que a taxa de retorno dos questionários respondidos foi de $87,75 \%$, sendo este um valor considerado alto quando se efetua este tipo de consulta.

As Figuras 1 a 5, mostradas a seguir, referem-se à qualidade percebida e à expectativa dos clientes participantes do estudo, de acordo com as cinco dimensões da qualidade abordadas pela Escala SERVQUAL: confiabilidade, empatia, sensibilidade, segurança e tangíveis.

Conforme Figura 1, as questões 5 (a clínica presta seus serviços no horário prometido); 14 (a fisioterapia é realizada conforme prometido); 9 (a clínica mantém dados pessoais atualizados dos pacientes); 7 (o fisioterapeuta é confiável) e 15 (o fisioterapeuta e a secretária executam seus serviços corretamente desde a primeira sessão) apresentaram avaliações positivas. Na dimensão Confiabilidade, em todas as questões, a percepção da qualidade dos serviços superou as expectativas sobre as mesmas. Segundo Fitzsimmons e Fitzsimmons (2005), quando as expectativas são excedidas, a qualidade pode ser considerada surpreendente.

Figura 1: Desempenho dos atributos da dimensão Confiabilidade.

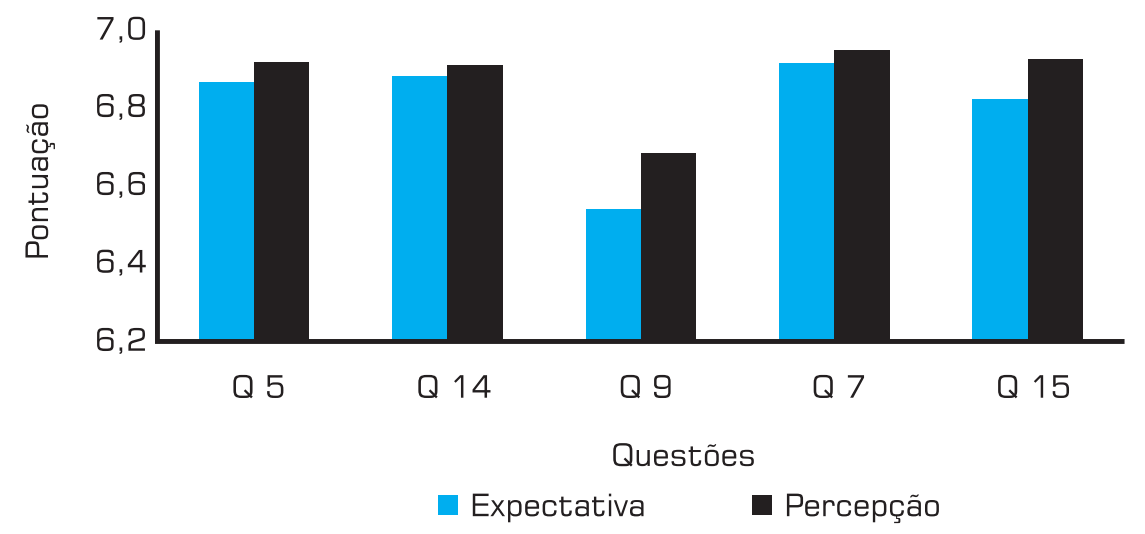


$\mathrm{Na}$ Figura 2, referente à dimensão Empatia, observa-se que as questões 21 (o fisioterapeuta se interessa pelo bemestar geral do paciente), 20 (o fisioterapeuta é atencioso com o paciente) e 18 (você recebe atenção individualizada, de acordo com as suas necessidades) apresentaram expectativa superior à qualidade percebida. Tal avaliação indica que essas questões merecem discussão junto à equipe profissional, pois se identificou uma lacuna entre o que os clientes desejam e o que estão recebendo dos profissionais. De acordo com Fitzsimmons e Fitzsimmons (2005), quando as expectativas não são atendidas, a qualidade é inaceitável. Somente a questão 6 da dimensão Empatia (o fisioterapeuta é compreensivo com as dificuldades apresentadas pelo paciente) apresentou qualidade percebida superior à qualidade desejada, significando que o serviço correspondeu às expectativas dos clientes.

O fato de a questão 6 apresentar avaliação positiva pode ser decorrência do maior acompanhamento dispensado pelo fisioterapeuta ao cliente que apresenta dificuldade na execução da técnica. Por outro lado, a avaliação das questões 21 , 20 e 18, cujas expectativas foram superiores à percepção, confirma o desejo dos clientes quanto a um atendimento diferenciado em que a relação fisioterapeuta-cliente não seja somente técnica, mas, também, voltada ao bem-estar geral dos clientes e aos aspectos do relacionamento humano. Demonstrar interesse pelos sentimentos e emoções dos

Figura 2: Desempenho dos atributos da dimensão Empatia.

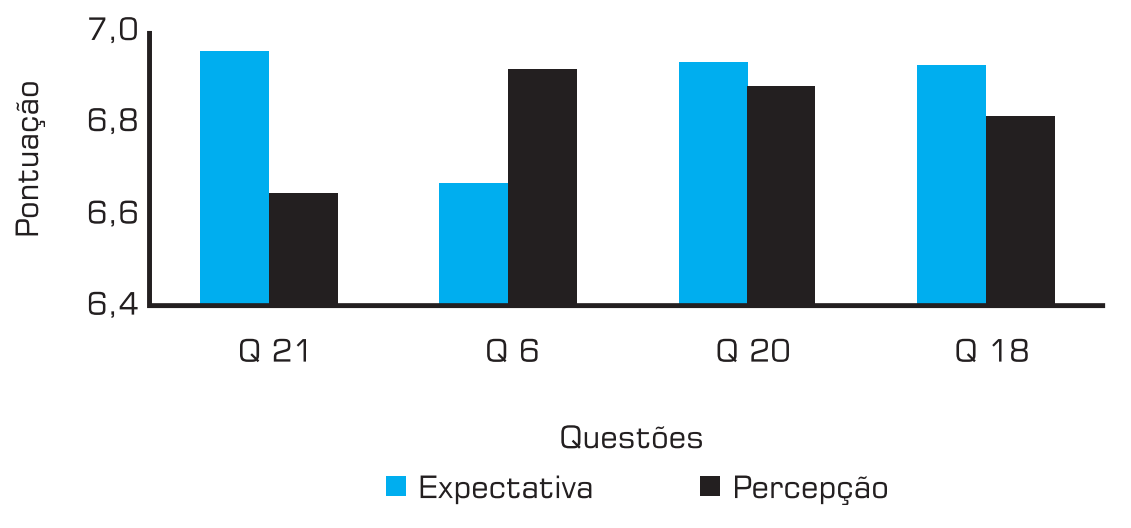

Figura 3: Desempenho dos atributos da dimensão Sensibilidade.

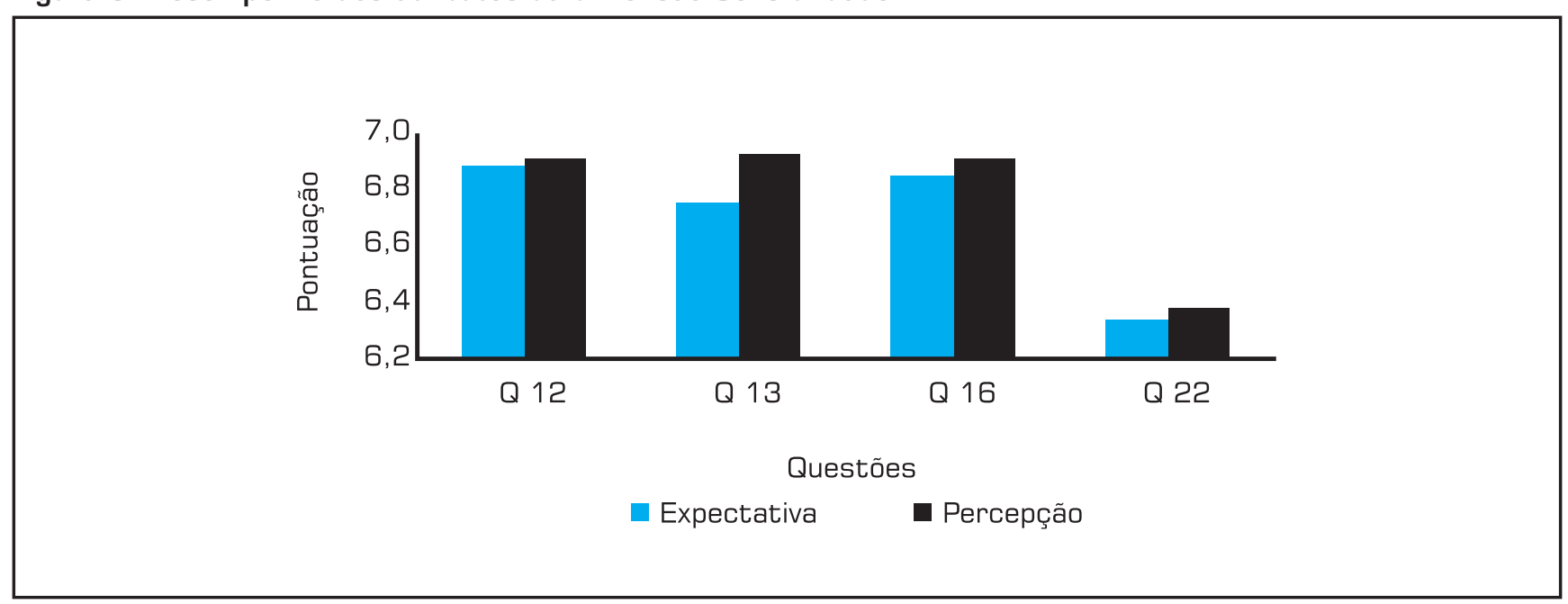


clientes, recordar-se dos problemas anteriores, ter paciência e boa capacidade para ouvir são atributos importantes para o profissional fisioterapeuta, na ótica dos clientes.

A Figura 3 mostra o desempenho dos atributos da dimensão Sensibilidade. As questões 12 (o fisioterapeuta utiliza linguagem clara e acessivel para se comunicar com o paciente) e 22 (o fisioterapeuta oferece horários convenientes ao paciente) apresentaram expectativa e percepção com valores muito próximos, o que representa oportunidade de melhoria nesses itens. Nas questões 13 (o fisioterapeuta tem conhecimento para responder as dúvidas do paciente) e 16 (a secretária é gentil e prestativa), a qualidade percebida superou as expectativas, demonstrando satisfação dos clientes.

A Figura 4 mostra o resultado das questões referentes à dimensão Segurança, a qual remete a conhecimento, habilidades, credenciais, reputação. Observam-se as três situações possíveis no confronto da qualidade percebida com a expectativa frente ao serviço:

Qualidade inaceitável: as questões 8 (a secretária passa informações precisas sobre o preço da sessão, datas e horários disponíveis, roupa adequada para a sessão de Fisioterapia) e 19 (o fisioterapeuta dá explicações sobre cada etapa do tratamento) merecem tratamento especial, visando à maior clareza nas informações repassadas aos clientes, pois as expectativas foram superiores à percepção da qualidade. A avaliação da questão 19 mostra que as explicações sobre a conduta do tratamento não foram dadas ou foram insuficientes para deixar o cliente ciente do tratamento.

Qualidade satisfatória: as questões 10 (o paciente sentese seguro ao ser atendido) e 17 (o fisioterapeuta explica a doença ao paciente) apresentaram expectativa e percepção com valores muito próximos, o que representa oportunidade de melhoria nesses itens.

Qualidade surpreendente: somente a questão 11 (o fisioterapeuta tem conhecimento para responder as dúvidas do paciente) mostrou qualidade percebida superior à expectativa.

\section{Astatística Multivariada aplicada à Escala SERVQUAL possibilitou um entendimento global dos resultados e uma correlação entre as variáveis.}

A Figura 5 mostra que as questões 1 (o fisioterapeuta possui equipamentos em ótimas condições) e 4 (o local de trabalho e os aparelhos estão limpos e organizados) apresentaram expectativa superior à qualidade percebida, representando oportunidade de melhoria para eliminar essa lacuna. As questões 3 (o fisioterapeuta e funcionários da clinica vestem-se bem e têm boa aparência) e 2 (as instalações físicas são bonitas e agradáveis) foram avaliadas positivamente, ou seja, qualidade percebida superior à expectativa.

$\mathrm{O}$ instrumento de coleta de dados continha, além do questionário baseado na Escala SERVQUAL, as dimensões da Escala SERVQUAL representadas, cada uma, por uma frase. O participante do estudo deveria distribuir o total de 100 pontos entre as cinco dimensões, atribuindo mais pontos para a(s) característica(s) que considerasse mais importante (s). Assim, conhecer-se-ia a importância atribuída a cada dimensão da qualidade. A Figura 6 apresenta esses resultados.

Figura 4: Desempenho dos atributos da dimensão Segurança.

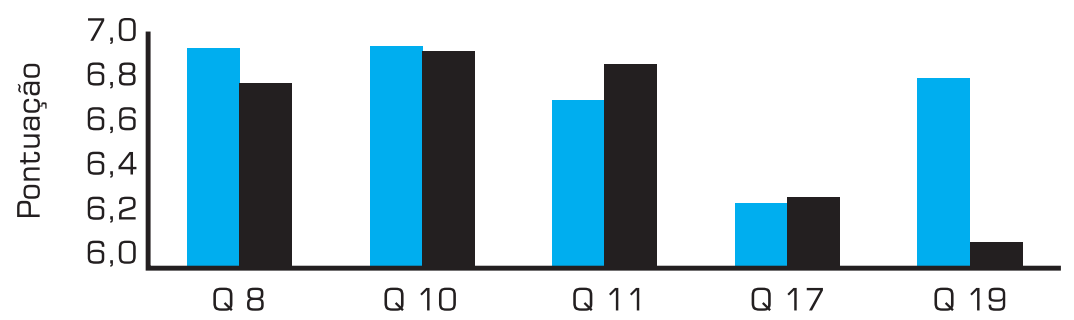

Questões

Expectativa

- Percepção 
Para os clientes participantes do estudo, a dimensão Segurança é a mais importante na composição da qualidade do serviço de Fisioterapia. Essa dimensão refere-se ao conhecimento e à cortesia dos funcionários bem como à capacidade de transmitir confiança e confidencialidade. A dimensão Segurança inclui ainda as seguintes características: competência para realizar o serviço, cortesia e respeito ao cliente, comunicação efetiva com o cliente e a idéia de que o funcionário está, realmente, interessado no melhor para o cliente. Esse resultado está de acordo com o que dizem Zeithaml e Bitner (2003): é provável que a dimensão Segurança seja particularmente importante nos serviços em que os clientes percebem que há alto risco envolvido e/ou quando estão incertos sobre sua habilidade para avaliar re- sultados, por exemplo, bancos, seguros, assistência médica e serviços advocatícios.

As Figuras 7 a 10 referem-se à Análise de Agrupamentos aplicada à Escala SERVQUAL. Observa-se a formação de vários clusters contendo questões semelhantes quanto à distância euclidiana. Pelo critério adotado, os objetos que possuem a menor distância entre si são mais semelhantes um ao outro do que os objetos com a maior distância.

O dendograma, com todas as questões referentes à EXPECTATIVA dos clientes, mostra a formação de dois clusters.

A análise da Figura 7 mostra o comportamento do dendograma com todas as variáveis (questões), no qual se pode identificar a formação de dois clusters, formados pelas

Figura 5: Desempenho dos atributos da dimensão Tangiveis.

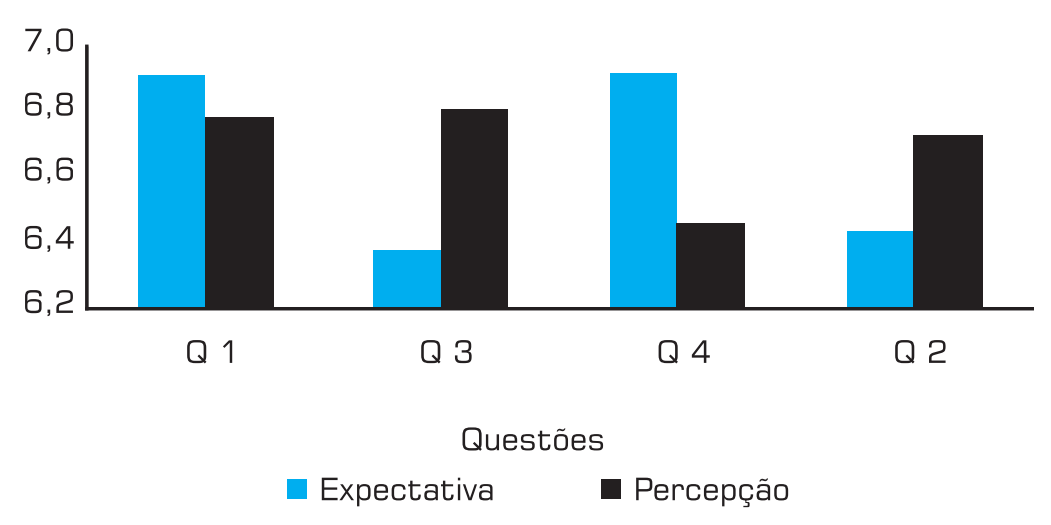

Figura 6: Desempenho dos atributos da dimensão da Escala SERVQUAL.

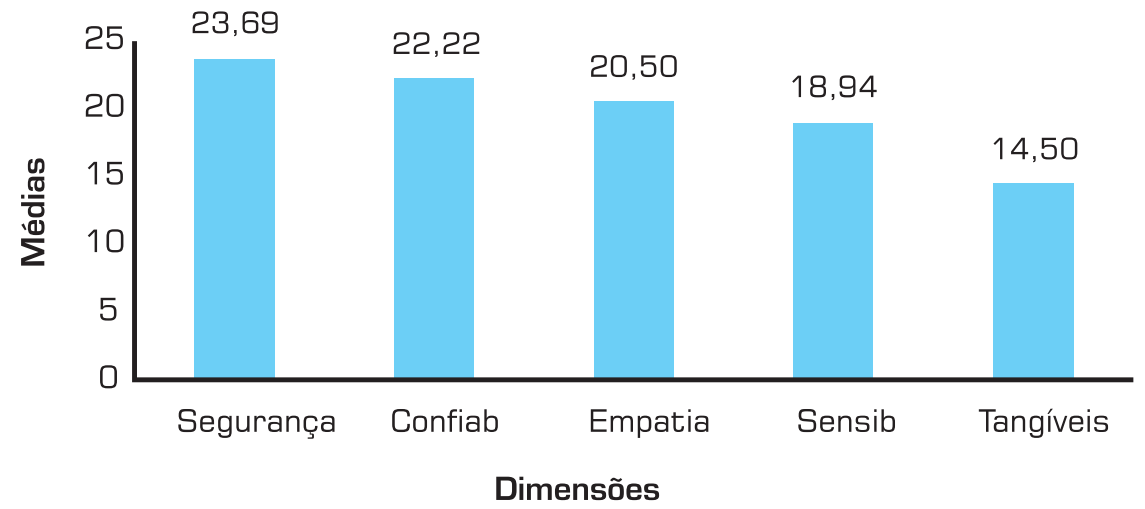


questões 20 e 1, como também 7 e 10. Quando duas ou mais questões são agrupadas num mesmo cluster, significa que a distância euclidiana entre elas é muito pequena. Neste estudo, isso revela que elas são semelhantes quanto ao seu grau de importância perante o cliente. Em outras palavras, para o cliente, elas têm a mesma representação quanto à importância quando ele imagina um excelente serviço de fisioterapia. Por isso, quando duas ou mais questões de uma mesma dimensão da qualidade foram agrupadas num mesmo cluster, pode-se excluir uma delas sem que haja diminuição na representatividade, abrangência ou qualidade do questionário.

Os clusters formados na Figura 7 envolvem a questão 20, pertencente à dimensão Empatia, e a questão 1 , pertencente à dimensão Tangíveis, e, por serem as questões de dimensões diferentes, não puderam ser excluídas, de acordo com os critérios fixados pelo pesquisador. $\mathrm{O}$ mesmo ocorre com as questões 7 e 10. Então, partiu-se para os clusters subseqüentes, mais abrangentes, como mostra a Figura 8.

Na Figura 08, o cluster à esquerda compreende as questões 18 e 20, pertencentes à dimensão Empatia, além da questão 1 , da dimensão Tangíveis. No entender do pesquisador, as questões 18 (é importante receber atenção individualizada, de acordo com as necessidades do paciente) e 20 (o fisioterapeuta deve ser atencioso com o paciente) remetem à idéia de atenção e, por isso, a questão 20 pode ser excluída, por estar subentendida na questão 18 . O cluster à direita da Figura 8 é formado pelas questões 4, 7, 10 e 8 , sendo que as questões 10 e 8 pertencem a uma mesma dimensão, ou seja, a dimensão Segurança. As questões 10 (o paciente deve sentir-se seguro ao ser atendido pelo fisioterapeuta) e 8 (a secretária deve passar informações precisas) foram mantidas no questionário, uma vez que se referem a diferentes profissionais, o que inviabiliza a exclusão de alguma delas. O gráfico obtido com a retirada da questão 20 é mostrado na seqüência.

Procedendo-se dessa maneira, treze questões puderam ser excluídas do questionário, sendo que o dendograma final apresentou a configuração que aparece na Figura 10:

Excluídas as variáveis de uma mesma dimensão, agrupadas num mesmo cluster e que remetiam a significados semelhantes, e permanecendo na análise as variáveis com distâncias euclidianas diferentes, procedeu-se à Análise Fatorial dessas variáveis. Através da geração de fatores, a Análise Fatorial possibilitou conhecer quais as variáveis mais importantes na formação da expectativa dos clientes e quanto cada fator contribuiu nessa construção. Aplicou-se a Análise Fatorial nas questões referentes às EXPECTA-

Figura 7: Dendograma com todas as questões referentes às expectativas dos clientes.

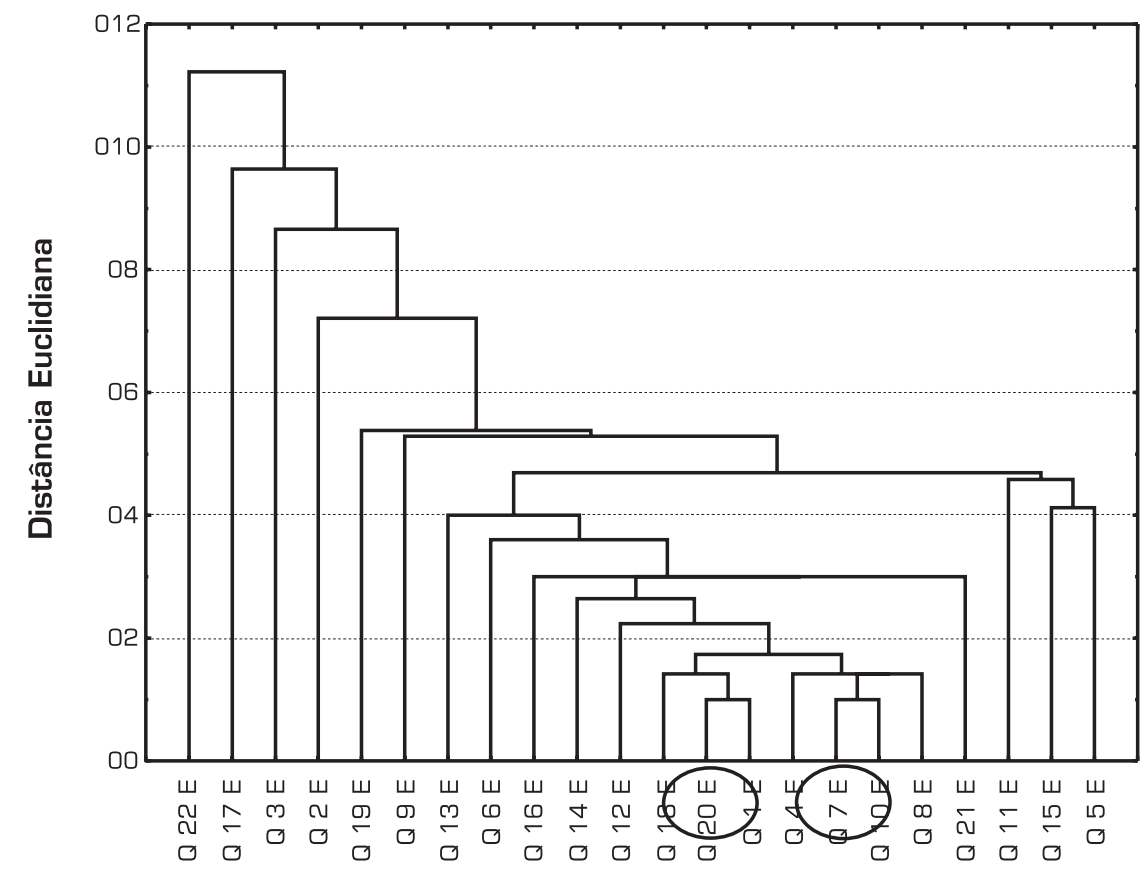


Figura 8: Dendograma mostrando a formação de dois clusters.

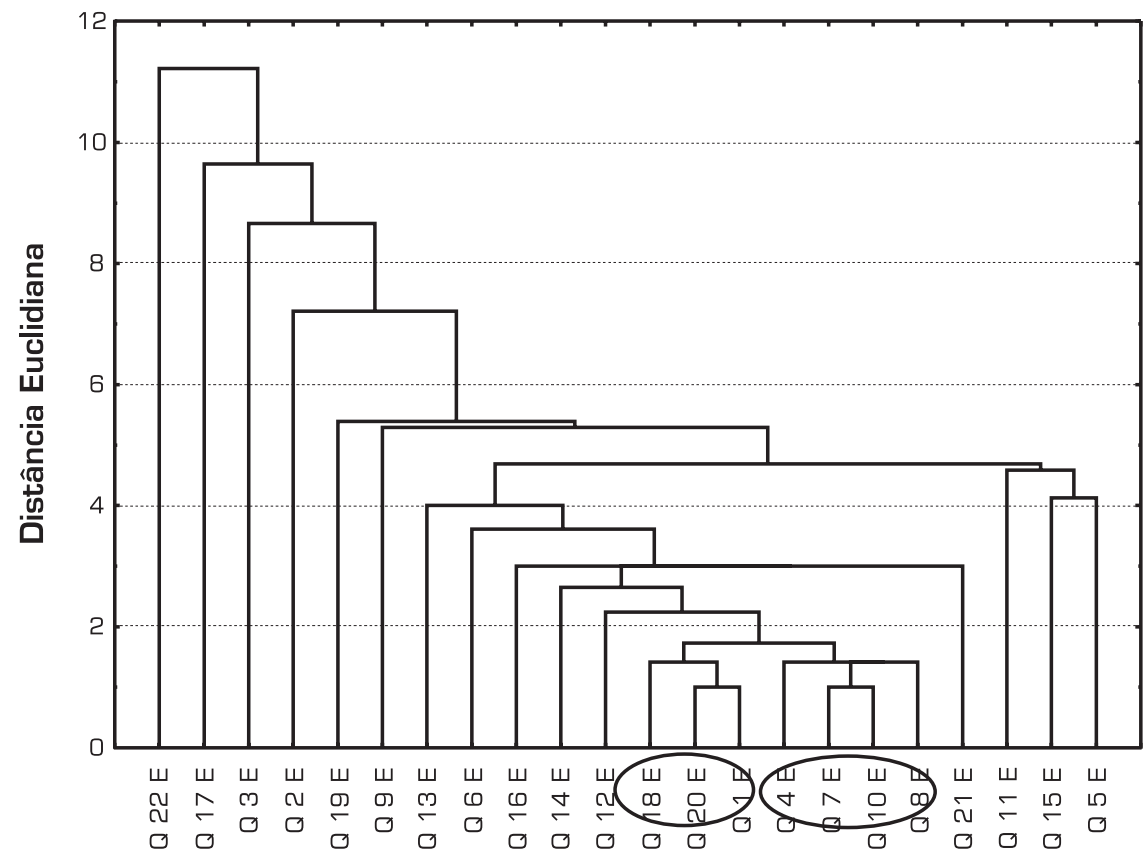

Figura 9: Dendograma após a retirada da questão 20.

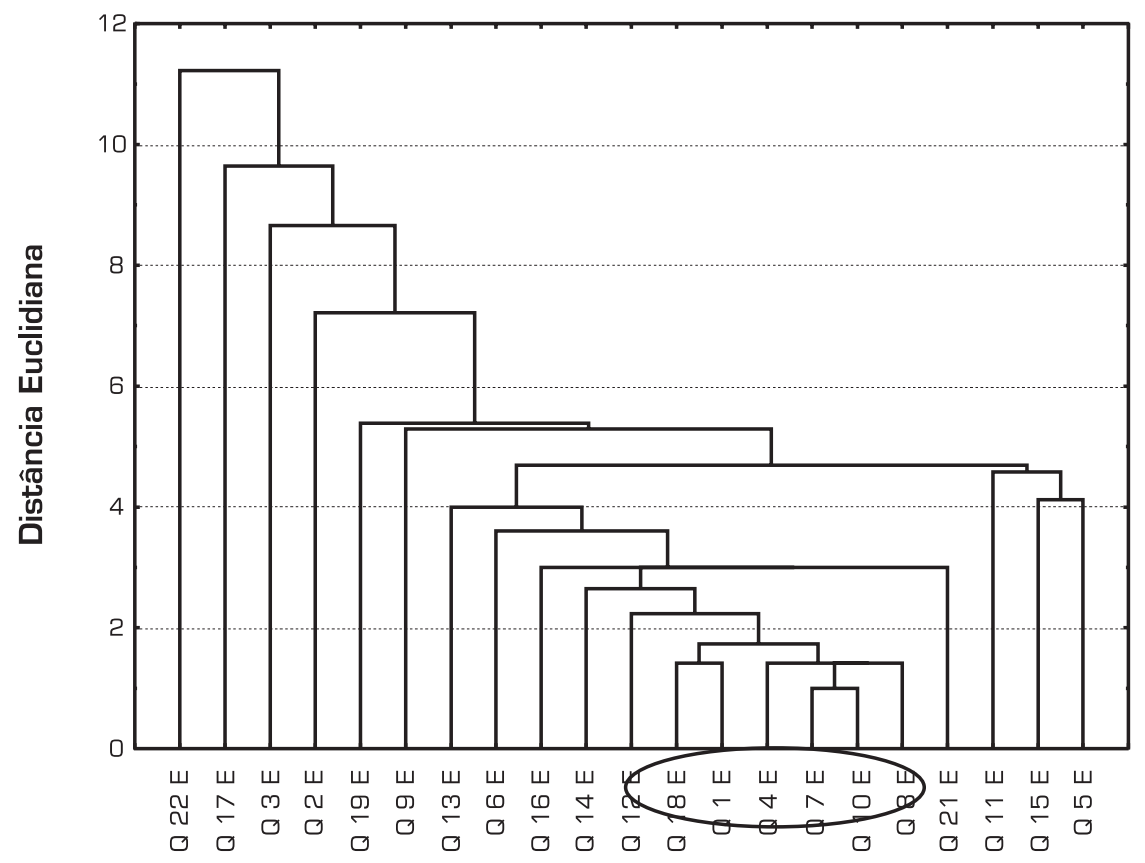


TIVAS, tanto no questionário completo (com 22 questões) quanto no questionário reduzido (com 13 questões). Com o intuito de validar o conjunto de dados para a aplicação da análise fatorial, foi investigada a estrutura de correlação dos mesmos por meio do teste de adequacidade de KaiserMeyer-Olkin, que forneceu um valor de 0,702. Este valor deve ser interpretado como se interpreta a magnitude de um coeficiente de correlação; logo, este teste valida a aplicação da Análise Fatorial. Outra medida que se utiliza é o teste de esfericidade de Bartlett, que forneceu um valor de 618,133 com 45 graus de liberdade e p-value de 0,000 , o que referenda o conjunto de dados para a análise. A Tabela 1 apresenta os resultados obtidos na Análise Fatorial.

A Tabela 1 mostra os autovalores, a variância explicada e a variância explicada acumulada quando utilizadas as 22 questões e quando utilizadas as 13 questões selecionadas pela Análise de Agrupamentos. Para a seleção dos fatores, adotou-se o método sugerido por Kaiser (1960, apud MARDIA, 1979), que consiste em incluir somente aqueles componentes cujos autovalores sejam superiores a 1 . No questionário completo, o número de fatores com autovalor superior a 1 foi seis, representando $86,553 \%$ da variância total dos dados. Quanto aos resultados da Escala SERVQUAL com 13 questões, somente os três primeiros fatores apresentaram autovalor superior a 1, sendo, então, considerados. O Fator 1 apresentou variância explicada de 53,706\%, superior à variância do Fator 1 do questionário completo, que foi de 45,326\%. Quanto à variância explicada acumulada, referente à Escala reduzida, os três fatores considerados somaram 78,912\%. Esse percentual foi ligeiramente inferior ao obtido com os seis fatores considerados no questionário completo $(86,553 \%)$, mostrando que o questionário original é redundante, pois houve uma diminuição de apenas $8,828 \%$ na variância total entre a Escala original e a reduzida. Assim, a síntese promovida na Escala SERVQUAL pela Análise de Agrupamentos foi aceita, pois a Análise Fatorial revelou que, com a retirada de nove questões da Escala, a mesma ainda apresentava 78,912\% de representação do real. Segundo Pereira (2001), não há valor crítico para essa representação do real, e, embora seja desejável algo superior a pelo menos $60 \%$, é o pesquisador que deve ajuizar se vale a pena a síntese provida por essa redução de dimensionalidade ou se deve preferir a abordagem exaustiva de considerar todas as variáveis.

A Tabela 2 reagrupa as questões segundo a composição de cada fator e não mais de acordo com as dimensões da Escala SERVQUAL.

Figura 10: Dendograma após a retirada da questões 20, 1, 14, 6, 5, 21, 11, 15 e 7.

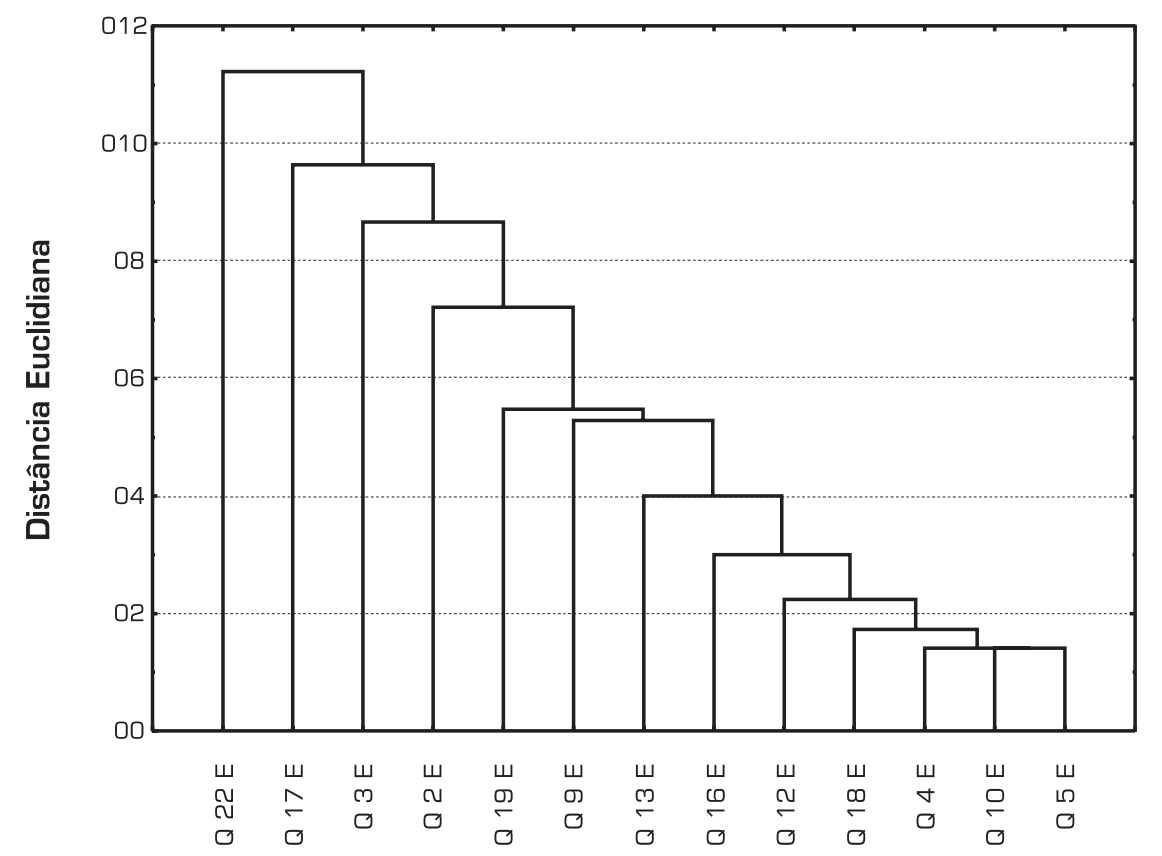


Conforme se observa na Tabela 2, o Fator 1 explica 45,33\% da variabilidade da Escala SERVQUAL, é formado pelas questões $8,10,7,4,19$ e 18 que, em conjunto, remetem à idéia de segurança. É importante salientar que quatro dimensões, das cinco que compõem a Escala SERVQUAL, estão presentes na composição do Fator 1, denotando sua abrangência e representatividade.

O Fator 2 é responsável pela explicação de 13,57\% da variabilidade da Escala e é composto pelas questões 21, 14 e 20 que, juntas, transmitem a idéia de empenho. Assim, das 22 questões integrantes da Escala SERVQUAL, 17 questões foram agrupadas em seis fatores pela Análise Fatorial, compreendendo aspectos de segurança, empenho, responsabilidade, dedicação, harmonia e consideração pelo cliente. Esses seis fatores respondem por $86,553 \%$ da variabilidade total dos dados.
Cabe ressaltar que os resultados apresentados na Figura 6, na qual a dimensão Segurança foi considerada a mais importante na composição da qualidade do serviço, estão de acordo com os resultados mostrados na Tabela 2, quanto ao Fator 1. Através de técnicas estatísticas diferentes, ou seja, Estatística Descritiva na Figura 6 e Análise Fatorial na Tabela 2, a dimensão Segurança mostrou-se fundamental para os clientes de Fisioterapia. Tal dimensão merece receber o devido valor por parte dos profissionais de saúde em geral, uma vez que a avaliação de qualidade desses serviços é influenciada fortemente pelo quanto de segurança os profissionais transmitem a seus clientes.

A Tabela 3 mostra quais questões da Escala reduzida pertencem a quais fatores e reagrupa-as, não mais de acordo com as dimensões do instrumento SERVQUAL.

Tabela 1: Autovalores e percentual de variância explicada.

\begin{tabular}{|c|c|c|c|c|c|c|}
\hline \multirow{3}{*}{ FATORES } & \multicolumn{3}{|c|}{ SERVQUAL COM 22 QUESTÕES } & \multicolumn{3}{|c|}{ SERVQUAL GOM 13 QUESTÕES } \\
\hline & \multirow[b]{2}{*}{ AUTOVALOBES } & VARIÂNGIA & VAR. EXPLIC. & \multirow[b]{2}{*}{ AUTOVALORES } & VARIÂNCIA & VAR. EXPLIC. \\
\hline & & $\begin{array}{c}\text { EXPLIGADA } \\
(\%)\end{array}$ & $\begin{array}{l}\text { ACUMULADA } \\
(\%)\end{array}$ & & $\begin{array}{c}\text { EXPLIGADA } \\
(\%)\end{array}$ & $\begin{array}{l}\text { AGUMULADA } \\
{[\%]}\end{array}$ \\
\hline 1 & 9,972 & 45,326 & 45,326 & 6,982 & 53,706 & 53,706 \\
\hline 2 & 2,985 & 13,569 & 58,896 & 2,119 & 16,303 & 70,009 \\
\hline 3 & 2,248 & 10,218 & 69,114 & 1,157 & 8,903 & 78,912 \\
\hline 4 & 1,434 & 6,517 & 75,631 & 0,821 & 6,316 & 85,228 \\
\hline 5 & 1,377 & 6,258 & 81,889 & 0,582 & 4,480 & 89,708 \\
\hline 6 & 1,026 & 4,663 & 86,553 & 0,384 & 2,950 & 92,659 \\
\hline 7 & 0,721 & 3,276 & 89,829 & 0,294 & 2,264 & 94,922 \\
\hline 8 & 0,563 & 2,559 & 92,388 & 0,216 & 1,664 & 96,586 \\
\hline 9 & 0,511 & 2,323 & 94,711 & 0,195 & 1,496 & 98,082 \\
\hline 10 & 0,381 & 1,733 & 96,444 & 0,129 & 0,993 & 99,075 \\
\hline 11 & 0,227 & 1,033 & 97,477 & 0,072 & 0,553 & 99,629 \\
\hline 12 & 0,182 & 0,829 & 98,306 & 0,046 & 0,355 & 99,984 \\
\hline 13 & 0,132 & 0,601 & 98,907 & 0,002 & 0,016 & 100,000 \\
\hline 14 & 0,106 & 0,483 & 99,390 & & & \\
\hline 15 & 0,086 & 0,392 & 99,782 & & & \\
\hline 16 & 0,038 & 0,174 & 99,956 & & & \\
\hline 17 & 0,007 & 0,034 & 99,990 & & & \\
\hline 18 & 0,002 & 0,010 & 100,000 & & & \\
\hline
\end{tabular}


A composição dos três fatores da escala reduzida assemelhou-se à composição dos seis fatores da escala original: o Fator 1 da escala original é formado pelas questões 8, 10, 7, 4, 19 e 18. Dessas, apenas as questões 10 e 19 não foram incluídas no Fator 1 da escala reduzida, sendo substituídas pelas questões 16 e 12 . Além disso, o Fator 1 da escala re- duzida abrigou questões pertencentes a todas as dimensões da Escala SERVQUAL, o que comprova sua consistência e representatividade. Em relação à sua variância explicada, seu valor foi, aproximadamente, 15,6\% superior ao Fator 1 da escala original, o que significa maior capacidade de explicação. A composição dos outros dois fatores da escala

Tabela 2: Classificação das questões de acordo com a Análise Fatorial.

\begin{tabular}{|c|c|c|c|c|c|}
\hline FATOR & $\begin{array}{l}\text { VARIÂNGIA } \\
\text { EXPLIGADA } \\
\text { (\%) }\end{array}$ & QUESTÃO & DIMENSÃO & SIGNIFICADO & $\begin{array}{l}\text { REMETEM À } \\
\text { IDÉIA DE }\end{array}$ \\
\hline \multirow{6}{*}{1} & \multirow{6}{*}{45,33} & 8 & Segurança & a secretária deve passar informações precisas & \multirow{6}{*}{ Segurança } \\
\hline & & 10 & Segurança & $\begin{array}{l}\text { o paciente deve sentir-se seguro ao ser } \\
\text { atendido pelo fisioterapeuta }\end{array}$ & \\
\hline & & 7 & Confiabilidade & o fisioterapeuta deve ser confiável & \\
\hline & & 4 & Tangíveis & $\begin{array}{l}\text { o local de trabalho e os aparelhos devem } \\
\text { estar limpos e organizados }\end{array}$ & \\
\hline & & 19 & Segurança & $\begin{array}{l}\text { o fisioterapeuta deve explicar cada etapa do } \\
\text { tratamento }\end{array}$ & \\
\hline & & 18 & Empatia & $\begin{array}{l}\text { é importante receber atenção } \\
\text { individualizada, de acordo com suas } \\
\text { necessidades }\end{array}$ & \\
\hline \multirow{3}{*}{2} & \multirow{3}{*}{13,57} & 21 & Empatia & $\begin{array}{l}\text { o fisioterapeuta deve interessar-se pelo } \\
\text { bem-estar geral do paciente }\end{array}$ & \multirow{3}{*}{ Empenho } \\
\hline & & 14 & Confiabilidade & $\begin{array}{l}\text { a fisioterapia deve ser realizada conforme } \\
\text { prometido }\end{array}$ & \\
\hline & & 20 & Empatia & $\begin{array}{l}\text { o fisioterapeuta deve ser atencioso com o } \\
\text { paciente }\end{array}$ & \\
\hline \multirow{3}{*}{3} & \multirow{3}{*}{10,22} & 5 & Confiabilidade & $\begin{array}{l}\text { a clínica deve prestar seus serviços no } \\
\text { horário prometido }\end{array}$ & \multirow{3}{*}{ Responsabilidade } \\
\hline & & 15 & Confiabilidade & $\begin{array}{l}\text { o fisioterapeuta e a secretária devem } \\
\text { executar seus serviços corretamente desde } \\
\text { a primeira sessão }\end{array}$ & \\
\hline & & 11 & Sensibilidade & $\begin{array}{l}\text { os dados dos pacientes devem ser } \\
\text { confidenciais, ou seja, mantidos em sigilo }\end{array}$ & \\
\hline 4 & 6,52 & 16 & Sensibilidade & a secretária deve ser gentil e prestativa & Dedicação \\
\hline \multirow{2}{*}{5} & \multirow{2}{*}{6,26} & 3 & Tangíveis & $\begin{array}{l}\text { o fisioterapeuta e funcionários da clínica devem } \\
\text { estar bem vestidos e ter boa aparência }\end{array}$ & \multirow{2}{*}{ Harmonia } \\
\hline & & 2 & Tangíveis & $\begin{array}{l}\text { as instalações físicas devem ser bonitas e } \\
\text { agradáveis }\end{array}$ & \\
\hline \multirow{2}{*}{6} & \multirow{2}{*}{4,66} & 17 & Segurança & $\begin{array}{l}\text { o fisioterapeuta deve explicar a doença ao } \\
\text { paciente }\end{array}$ & \multirow{2}{*}{$\begin{array}{l}\text { Consideração } \\
\text { pelo cliente }\end{array}$} \\
\hline & & 22 & Sensibilidade & $\begin{array}{l}\text { o fisioterapeuta deve oferecer horários } \\
\text { convenientes ao paciente }\end{array}$ & \\
\hline
\end{tabular}


reduzida assemelhou-se à composição dos fatores originais só em número reduzido de questões.

Após realizada a Análise Multivariada nas variáveis envolvidas no estudo, procurou-se verificar a existência de diferença significativa entre a expectativa e a percepção nos quesitos examinados. Para tal, foi testada a normalidade dos dados por meio do teste Shapiro-Wilk, o qual forneceu estatística do teste de $\mathrm{W}=0,95482$ com $p$-valor igual a 0,00438 , mostrando que os dados não seguem uma distribuição normal. Logo, a comparação entre as questões referentes à expectativa e as questões referentes à percepção foi realizada por meio do teste de Wilcoxon (CALLEGARIJACQUES, 2003).

Os pares de variáveis Q5, Q14, Q1, Q6, Q9, Q17, Q7, Q15, Q11, Q16, Q12 e Q13 mostraram não haver diferença significativa entre a expectativa e a percepção, sendo que o p-valor para o teste de Wilcoxon foi maior do que 0,05 , isto é, $\mathrm{p}>5 \%$. As demais variáveis apresentaram diferença significativa entre a expectativa e a percepção, conforme mostra a Tabela 4.

Pode-se observar que, como todos os valores de $p$-valor são menores do que 5\%, existe uma diferença significativa entre a expectativa e a percepção do cliente nos quesitos listados na Tabela 4. Importante salientar que, cada vez que o cliente teve uma média de percepção maior do que a média da expectativa, significa que o cliente foi atendido acima do esperado.

Com base em observações feitas pelos respondentes do questionário quanto a alguns termos utilizados nas perguntas e devido à pertinência das mesmas, optou-se pela substituição de algumas palavras ou frases por outras mais adequadas. Assim, o questionário sugerido pela Análise de Agrupamentos e Análise Fatorial foi reformulado e apresenta a configuração que aparece na Tabela 5.

Importante destacar que o questionário sugerido na Tabela 5 pode ser aplicado em outros segmentos da área da saúde com vistas à avaliação da qualidade de seus serviços, em especial aos serviços médicos, odontológicos, de nutrição, fonoaudiologia, psicologia, e enfermagem. Além disso, sua aplicabilidade não se restringe à área da saúde, desde que realizadas as adaptações pertinentes ao setor abordado. Em relação às técnicas estatísticas aplicadas, ou seja, Análise de Agrupamentos e Análise Fatorial, o seu emprego em modelos distintos da Escala SERVQUAL depende dos resultados

Tabela 3: Classificação das questões selecionadas pela Análise de Agrupamentos após aplicação da Análise Fatorial.

\begin{tabular}{|c|c|c|c|c|c|}
\hline FATOR & $\begin{array}{c}\text { VARIÂNCIA } \\
\text { EXPLIGADA } \\
\text { (\%) }\end{array}$ & QUESTÃO & DIMENSÃO & SIGNIFIGADO & $\begin{array}{l}\text { REMETEM À } \\
\text { IDÉIA DE }\end{array}$ \\
\hline \multirow{6}{*}{1} & \multirow{6}{*}{53,706} & 8 & Segurança & a secretária deve passar informações precisas & \multirow{6}{*}{ Segurança } \\
\hline & & 7 & Confiabilidade & o fisioterapeuta deve ser confiável & \\
\hline & & 4 & Tangíveis & $\begin{array}{l}\text { o local de trabalho e os aparelhos devem estar } \\
\text { limpos e organizados }\end{array}$ & \\
\hline & & 18 & Empatia & $\begin{array}{l}\text { é importante receber atenção individualizada, } \\
\text { de acordo com suas necessidades }\end{array}$ & \\
\hline & & 16 & Sensibilidade & a secretária deve ser gentil e prestativa & \\
\hline & & 12 & Sensibilidade & $\begin{array}{l}\text { o fisioterapeuta deve utilizar linguagem clara e } \\
\text { acessível para se comunicar com o paciente }\end{array}$ & \\
\hline \multirow{2}{*}{2} & \multirow{2}{*}{16,303} & 3 & Tangíveis & $\begin{array}{l}\text { o fisioterapeuta e os funcionários da clínica } \\
\text { devem estar bem vestidos e ter boa aparência }\end{array}$ & \multirow{2}{*}{ Harmonia } \\
\hline & & 2 & Tangíveis & $\begin{array}{l}\text { as instalações físicas devem ser bonitas e } \\
\text { agradáveis }\end{array}$ & \\
\hline \multirow{2}{*}{3} & \multirow{2}{*}{8,903} & 17 & Segurança & $\begin{array}{l}\text { o fisioterapeuta deve explicar a doença ao } \\
\text { paciente }\end{array}$ & \multirow{2}{*}{$\begin{array}{l}\text { Consideração } \\
\text { pelo cliente }\end{array}$} \\
\hline & & 22 & Sensibilidade & $\begin{array}{l}\text { o fisioterapeuta deve oferecer horários } \\
\text { convenientes ao paciente }\end{array}$ & \\
\hline
\end{tabular}


obtidos em cada pesquisa. Assim, a análise preliminar dos resultados revelará a necessidade ou não do emprego de técnicas multivariadas.

\section{CONSIDERAC̣̃̃ES FINAIS}

Os resultados anteriormente apresentados permitem concluir que:

1) O instrumento SERVQUAL possibilita comparar as expectativas e percepções sobre a prestação de serviços fisioterápicos. Nesse sentido, das 22 questões que compunham a Escala, em 12 delas a percepção de qualidade foi superior às expectativas. Três questões apresentaram médias muito parecidas entre as expectativas e percepções e, em sete questões, as expectativas foram superiores às percepções.

2) As questões deficientes referem-se às seguintes dimensões: Empatia, Segurança e Tangíveis.

3) A dimensão Segurança mostrou-se a mais importante no julgamento dos clientes participantes do estudo.

4) A aplicação de Estatística Multivariada mostrou a presença de questões redundantes no questionário SERVQUAL adaptado ao estudo de caso, o que permitiu a retirada de algumas questões mediante critérios de exclusão. Assim, nove questões foram eliminadas do questionário, acarretando uma diminuição de apenas $8,828 \%$ na variância total entre o questionário aplicado e o reduzido.

5) Sugere-se, então, que futuras pesquisas adotem o questionário mais enxuto, o qual é composto por treze questões, em vez das vinte e duas utilizadas no presente estudo. A adoção do questionário reduzido proporcionará maior confiabilidade do respondente na pesquisa, pois não haverá questões transmitindo o mesmo grau de informação ao cliente. Além disso, como as questões da Escala SERVQUAL estão estruturadas aos pares, a retirada de nove questões referentes à expectativa implica a retirada das respectivas questões referentes à percepção. Assim, o total de questões a ser respondido no questionário mais enxuto será de vinte e seis, sendo que o questionário aplicado neste estudo de caso continha quarenta e quatro. Com isso, dar-se-á maior agilidade à coleta de dados sem que haja, contudo, perda na abrangência e confiabilidade do instrumento.

\section{A aplicação de Estatística Multivariada mostrou a presença de questões redundantes no questionário SERVQUAL adaptado ao estudo de caso.}

A contribuição deste trabalho para a Engenharia de Produção consiste na aplicação da ferramenta SERVQUAL, amplamente difundida na literatura sobre serviços, em um serviço de saúde, como é o caso da clínica de Fisioterapia constituinte do caso. Além disso, este trabalho propôs um questionário com menor número de questões, sem perda significativa em sua abrangência. Outros segmentos do setor de serviços poderão se beneficiar da versão mais enxuta da ferramenta SERVQUAL, não restrita à área da saúde, e facilitar suas pesquisas. Além disso, o tema pesquisado também é de substancial relevância para a Fisioterapia, uma vez que

Tabela 4: Valores da estatística exata do teste de Wilcoxon, com as respectivas médias para a expectativa e para a percepção.

\begin{tabular}{|c|c|c|c|}
\hline VARIÁVEL & P-VALOR & MÉDIA EXPECTATIVA & MÉDIA PERGEPĢÃO \\
\hline Q 21 & 0,002821 & 6,9186 & 6,5930 \\
\hline Q 8 & 0,010594 & 6,9419 & 6,8023 \\
\hline Q10 & 0,019224 & 6,9651 & 6,8256 \\
\hline Q 20 & 0,007399 & 6,9419 & 6,7326 \\
\hline Q 22 & 0,018838 & 6,1163 & 6,5581 \\
\hline Q 4 & 0,002902 & 6,9419 & 6,7209 \\
\hline Q 19 & 0,001677 & 6,7326 & 6,3765 \\
\hline Q 18 & 0,007686 & 6,9535 & 6,8000 \\
\hline Q 2 & 0,008572 & 6,4706 & 6,7791 \\
\hline
\end{tabular}


possibilita conhecer um pouco mais a respeito de como os clientes definem qualidade. Assim, pesquisas nessa área têm importância tanto para os profissionais da saúde como para a Engenharia de Produção.

Quanto a trabalhos futuros, a primeira possibilidade é repetir a pesquisa em outros segmentos de atuação da Fisioterapia, além da Ortopedia e Traumatologia. A segunda possibilidade é aplicar o questionário a clientes atendidos pelo Sistema Único de Saúde, para conhecer suas expectativas e verificar se diferem das expectativas de clientes particulares. Paralelamente às necessidades por pesquisa na área de qualidade de serviços e satisfação de clientes externos, também existe uma demanda pela pesquisa em serviços internos, ou seja, com os prestadores de serviço. Assim, pode-se sugerir um terceiro tema para pesquisas futuras: aplicar o questionário a fisioterapeutas para conhecer o que é qualidade no entender desses profissionais e comparar estes resultados com as expectativas de seus clientes.

Por fim, a existência de outros modelos propostos na literatura para avaliar a qualidade em serviços configura-se em mais uma possibilidade de pesquisa, uma vez que diferentes modelos podem ser aplicados ao segmento de saúde para se descobrir qual modelo é o mais apropriado.

Tabela 5: Sugestão de questionário baseado na Escala SERVQUAL.

\begin{tabular}{|c|c|c|}
\hline QUESTÃO & DIMENSÃO & SIGNIFIGADO \\
\hline 01 & Segurança & A secretária deve passar informações precisas. \\
\hline 02 & Segurança & Os dados dos clientes devem ser confidenciais, ou seja, mantidos em sigilo. \\
\hline 03 & Segurança & O fisioterapeuta deve explicar cada etapa do trabalho. \\
\hline 04 & Segurança & O fisioterapeuta deve explicar a enfermidade ao cliente. \\
\hline 05 & Segurança & $\begin{array}{l}\text { O fisioterapeuta deve utilizar linguagem clara e acessível para se comunicar } \\
\text { com o cliente. }\end{array}$ \\
\hline 06 & Sensibilidade & $\begin{array}{l}\text { O fisioterapeuta deve ter conhecimento para responder às dúvidas do } \\
\text { cliente. }\end{array}$ \\
\hline 07 & Sensibilidade & O fisioterapeuta deve oferecer horários convenientes ao cliente. \\
\hline 08 & Confiabilidade & O fisioterapeuta deve ser confiável. \\
\hline 09 & Confiabilidade & $\begin{array}{l}\text { O fisioterapeuta e a secretária devem executar seus serviços corretamente } \\
\text { desde a primeira sessão. }\end{array}$ \\
\hline 10 & Tangíveis & O fisioterapeuta e funcionários da clínica devem vestir-se adequadamente. \\
\hline 11 & Tangíveis & As instalações físicas devem ser agradáveis. \\
\hline 12 & Tangíveis & O local de trabalho e os aparelhos devem estar limpos e organizados. \\
\hline 13 & Empatia & $\begin{array}{l}\text { Você deve receber atenção individualizada, de acordo com as suas } \\
\text { necessidades. }\end{array}$ \\
\hline
\end{tabular}

\section{Artigo recebido em 17/04/2007}

Aprovado para publicação em 27/08/2007 


\section{- References}

CALLEGARI-JACQUES, S. M. Bioestatística - princípios e aplicações. Artmed: Porto Alegre, 2003

CHOI, K.; CHO, W.; LEE, S.; LEE, H.; KIM, C. The relationships among quality, value, satisfaction and behavioral intention in health provider choice: a south Korean study. Journal of Business Research, v. 57 p. 913-921, 2004.

DEMING, W. E. Qualidade: a Revolução da Administração. Rio de Janeiro: MarquesSaraiva, 1990.

DONABEDIAN, A. The Seven Pilars of Quality. Arch Pathol Med., n. 114, 1990.

FITZSIMMONS, J. A.; FITZSIMMONS, M. J. Administração de serviços: operações, estratégia e tecnologia de informação. 4. ed. Porto Alegre: Bookman, 2005.

FRANCE, K. R.; GROVER, R. What is the health care product? Journal of Health Care Marketing, Boone, v. 12, n. 2, p. 31-38, June 1992

GEMMEL, P.; DE MAN, S.; VLERICK, P.; RIJK, P. V.; DIERCKX, R. Patients' and personnel's perceptions of service quality and patient satisfaction in nuclear medicine. European Journal of nuclear medicine and molecular imaging, v. 29, n. 9, p. 1109-17, 2002.

HAIR, J. F.; ANDERSON, R. E.; TATHAM, R. L.; BLACK, W. C. Análise multivariada de dados. 5. ed. Porto Alegre, 2005.

GRÖNROOS, C. Marketing - gerenciamento e serviços. Rio de Janeiro: Elsevier, 2003.

JOHNSTON, R.; CLARK, R. Administração de operações de serviço. São Paulo: Atlas, 2002

KARATEPE, O. M.; YAVA U.; BABAKUS E. Measuring service quality of banks: scale development and validation. Journal of Retailing and Consumer Services, v. 12, n. 5, p. 373-838, 2005.

KHATTREE, R.; NAIK, D. N. Multivariate data reduction and discrimination with SAS Software. Cary, NC: SAS Institute Inc., 2000.

MALHOTRA, N. K. Pesquisa de Marketing uma orientação aplicada. 3. ed. Porto Alegre: Bookmann, 2001.
MARDIA, K. V.; KENT, J. T.; BIBBY, J. Multivariate analysis. London: Academic, 1979.

MIGUEL, P. A. C.; SALOMI, G. E. Uma revisão dos modelos para medição da qualidade em serviços. Revista Produção, v. 14, n. $1,2004$.

MINGOTI, S. A. Análise de dados através de métodos de estatística multivariada: uma abordagem aplicada. Belo Horizonte: UFMG, 2005.

MIRSHAWKA, $V$. Hospital: fui bem atendido, a vez do Brasil. São Paulo: Makron Books, 1994

PALADINI, E. P. Gestão da qualidade no processo: a qualidade na produção de bens e serviços. São Paulo: Atlas, 1995.

PARASURAMAN, A.; ZEITHAML, V. A.; BERRY, L. L. A conceptual model of service quality and its implications for future research. Journal of Marketing, v. 49, n. 3, p. 41-50, 1985

PARASURAMAN, A.; ZEITHAML, V. A. BERRY, L. L. Refinement and reassessment of the Servqual Scale. Journal of Retailing, v. 67, n. 4, p. 420-50, 1991.
PEREIRA, J. C. R. Análise de dados qualitativos: estratégias metodológicas para as ciências da saúde, humanas e sociais. São Paulo: Edusp, 2001

SANTOS, N. S. Componentes e atributos que configuram a qualidade na relação médicopaciente. 2004. 123f. Tese (Doutorado em Engenharia de Produção). Universidade Federal de Santa Catarina, Florianópolis, 2004

SOUZA, A. M.; VICINI, L. Análise multivariada da teoria à prática. Santa Maria: Departamento de Estatística UFSM. 2005.

URDAN, A. T. A qualidade de serviços médicos na perspectiva do cliente. Revista de Administração de Empresas. São Paulo, v. 41, n. 4, p. 44-55, out./dez. 2001.

ZEITHAML, V. A.; BITNER, M. J. Marketing de serviços: a empresa com foco no cliente. 2. ed. Porto Alegre: Bookman, 2003.

\section{- Sobre os autores}

Adriano Mendonça Souza, Dr.

Universidade Federal de Santa Maria

Faixa de Camobi, km 9 - Campus Universitário - prédio 13 - sala 1205 C - Santa Maria - RS - CEP 97105-900

Fone: (55) 3220-8486; fax: (55) 3220-8612

E-mail: amsouza@smail.ufsm.br

\section{Deizi Griebeler, Ms.}

Pós-graduação em Engenharia de Produção - Universidade Federal de Santa Maria

Rua Presidente Kennedy, 977 - sala 502 - Frederico Westphalen - RS - CEP 98400-000

Fone: (55) 3744-2962

E-mail: deizigriebeler@terra.com.br

\section{Leoni Pentiado Godoy, Dra.}

Universidade Federal de Santa Maria

Faixa de Camobi, km 9 - Campus Universitário

Departamento de Engenharia de Produção e Sistemas - Centro de Tecnologia - Santa Maria - RS - CEP 97105-900

Fone: (55) 3220-8442

E-mail: leoni@smail.ufsm.br 


\section{ANEXO — QUESTIONÁRIO PARA AVALIAC̣ÃO DA QUALIDADE EM SERVIC̣OS DE FISIOTERAPIA}

\section{AVALIAĈ̣̃O DA EXPECTATIVA SOBRE O SERVIC̣O}

Por favor, indique o grau que você acha que os Fisioterapeutas deveriam apresentar das características descritas em cada questão. Faça isso assinalando um dos sete números após cada enunciado. Se você concorda plenamente que os Fisioterapeutas deveriam ter determinada característica, circule o número 7. Se você discorda totalmente de que os Fisioterapeutas deveriam possuir essa característica, circule o número 1. Em situações intermediárias, assinale um número entre 2 e 6 , de acordo com seu grau de concordância com o enunciado.

\begin{tabular}{|c|c|c|c|c|c|c|c|}
\hline \multirow{2}{*}{$\begin{array}{l}\text { Questões sobre a expectativa do serviço } \\
5 \text { - A clínica deve prestar seus serviços no horário prometido. }\end{array}$} & \multicolumn{7}{|c|}{$\begin{array}{l}1 \text { = discordo totalmente } \\
7=\text { concordo totalmente } \\
2 \text { a } 6 \text { = situações intermediárias }\end{array}$} \\
\hline & 1 & 2 & 3 & 4 & 5 & 6 & 7 \\
\hline $\begin{array}{l}21 \text { - Deve-se esperar que o fisioterapeuta se interesse pelo bem-estar } \\
\text { geral do paciente. }\end{array}$ & 1 & 2 & 3 & 4 & 5 & 6 & 7 \\
\hline $\begin{array}{l}8 \text { - A secretária deve passar informações precisas sobre o preço da } \\
\text { sessão, datas e horários disponíveis, roupa adequada para a sessão de } \\
\text { fisioterapia. }\end{array}$ & 1 & 2 & 3 & 4 & 5 & 6 & 7 \\
\hline 14 - A fisioterapia deve ser realizada conforme prometido. & 1 & 2 & 3 & 4 & 5 & 6 & 7 \\
\hline 1 - O fisioterapeuta deve utilizar equipamentos em ótimas condições. & 1 & 2 & 3 & 4 & 5 & 6 & 7 \\
\hline $\begin{array}{l}6 \text { - O fisioterapeuta deve ser compreensivo com as dificuldades } \\
\text { apresentadas pelo paciente. }\end{array}$ & 1 & 2 & 3 & 4 & 5 & 6 & 7 \\
\hline 10 - O paciente deve se sentir seguro ao ser atendido pelo fisioterapeuta. & 1 & 2 & 3 & 4 & 5 & 6 & 7 \\
\hline $\begin{array}{l}3 \text { - O fisioterapeuta e funcionários da clínica devem estar bem vestidos e } \\
\text { ter boa aparência. }\end{array}$ & 1 & 2 & 3 & 4 & 5 & 6 & 7 \\
\hline 9 - As clínicas devem ter dados pessoais atualizados dos pacientes. & 1 & 2 & 3 & 4 & 5 & 6 & 7 \\
\hline 17 - O fisioterapeuta deve explicar a doença ao paciente. & 1 & 2 & 3 & 4 & 5 & 6 & 7 \\
\hline 7 - O fisioterapeuta deve ser confiável. & 1 & 2 & 3 & 4 & 5 & 6 & 7 \\
\hline 20 - O fisioterapeuta deve ser atencioso com o paciente. & 1 & 2 & 3 & 4 & 5 & 6 & 7 \\
\hline 22 - 0 fisioterapeuta deve oferecer horários convenientes ao paciente. & 1 & 2 & 3 & 4 & 5 & 6 & 7 \\
\hline 4 - O local de trabalho e os aparelhos devem estar limpos e organizados. & 1 & 2 & 3 & 4 & 5 & 6 & 7 \\
\hline $\begin{array}{l}15 \text { - O(s] fisioterapeuta[s] e a secretária devem executar seus serviços } \\
\text { corretamente desde a primeira sessão. }\end{array}$ & 1 & 2 & 3 & 4 & 5 & 6 & 7 \\
\hline
\end{tabular}




\begin{tabular}{|c|c|c|c|c|c|c|c|}
\hline $\begin{array}{l}19 \text { - O fisioterapeuta deve explicar ao paciente cada etapa do } \\
\text { tratamento. }\end{array}$ & 1 & 2 & 3 & 4 & 5 & 6 & 7 \\
\hline $\begin{array}{l}11 \text { - Os dados dos pacientes devem ser confidenciais, ou seja, mantidos } \\
\text { em sigilo. }\end{array}$ & 1 & 2 & 3 & 4 & 5 & 6 & 7 \\
\hline $\begin{array}{l}18 \text { - É importante receber atenção individualizada, de acordo com as } \\
\text { necessidades do paciente. }\end{array}$ & 1 & 2 & 3 & 4 & 5 & 6 & 7 \\
\hline 16 - A secretária deve ser gentil e prestativa. & 1 & 2 & 3 & 4 & 5 & 6 & 7 \\
\hline $\begin{array}{l}12 \text { - O fisioterapeuta deve utilizar linguagem clara e acessível para se } \\
\text { comunicar com o paciente. }\end{array}$ & 1 & 2 & 3 & 4 & 5 & 6 & 7 \\
\hline 2 - As instalações físicas devem ser bonitas e agradáveis. & 1 & 2 & 3 & 4 & 5 & 6 & 7 \\
\hline $\begin{array}{l}13 \text { - O fisioterapeuta deve ter conhecimento para responder às dúvidas } \\
\text { do paciente. }\end{array}$ & 1 & 2 & 3 & 4 & 5 & 6 & 7 \\
\hline
\end{tabular}

\section{AVALIAC̣ÃO DA PRESTAÇÃ̃o DO SERVIC̣O}

As questões referentes à avaliação da prestação do serviço seguem a seqüência do questionário sobre a expectativa do serviço, mudando-se, apenas, o seu tempo verbal. Por exemplo: a clínica presta seus serviços no horário prometido. 